\title{
Quinientos años de diccionarios en portugués
}

\author{
IGNACIO VÁZQUEZ DIÉGUEZ \\ Universitat de Barcelona
}

\section{INTRODUCCIÓN}

Nos proponemos en las siguientes páginas dar a conocer al público español y, en general, a cualquier lector, los diccionarios monolingües portugueses; pero no solo ésos, también los bilingües que les antecedieron - básicamente latín/portugués, ya que sin ellos no se entendería la lexicografía portuguesa-, y los primeros bilingües con una lengua viva.

La particular historia de la lengua portuguesa en sus aspectos sociopolíticos ha provocado que el nacimiento de su lexicografía monolingüe fuese tardía en relación con la de otros países. Francia (Richelet, 1680), Italia (Accademia della Crusca, 1612) y España (Covarrubias, 1611) muestran sus primeros diccionarios escritos enteramente en la lengua vernácula a lo largo del siglo XVII, Portugal deberá esperar a finales del XVIII (Cândido Lusitano, 1765; aunque se considere Morais, 1789).

La presencia del latín como lengua vehicular en la enseñanza y en los escritos científicos portugueses hasta bien entrado el siglo XVIII fue una de las causas de esa espera, pero como se verá, quizás no la más importante dado que la producción de diccionarios bilingües [portugués/lengua no europea] es ingente, lo cual demuestra la importancia dada a las (ex)colonias (y a la evangelización).

\section{SIEMPRE EL LATÍN}

El diccionario es un producto de la actividad lingüística. En Europa, los antecedentes más antiguos que tenemos de esa actividad son los del período clásico — Grecia y Roma-: tratados de gramática, de etimología, summae de carácter enciclopédico y glosarios. ${ }^{1}$

Durante la Edad Media, el estudio de la lengua se centró en la gramática, voz que hasta prácticamente el siglo XII era sinónima de latín. Explica Azorín (2000: 15) que el

${ }^{1}$ Varrón (116-27 aC) con su De lingua latina, Dionisio de Tracia (170-90 aC), Plinio (23-79) con su Naturalis Historia, Suetonio (69-140) con su De grammaticis, Donato (s. IV) con su Ars grammatica (dividido en Ars minor y Ars maior) y San Isidoro de Sevilla (560-636) con su Originum sive Etimologiarum libri fueron las figuras esenciales de la Antigüedad. 
latín se convirtió en la lengua franca de las elites intelectuales pero «sin el apoyo del uso cotidiano, el latín debe ser estudiado como una segunda lengua. Desde ese momento, roto el sistema escolar de la Antigüedad, se impone la reorganización de la enseñanza del latín desde esta nueva perspectiva, lo que habrá de propiciar la aparición de instrumentos didácticos adaptados a las necesidades específicas de los aprendices». Y aquí es donde la lexicografía dará sus primeros pasos en la Europa medieval. Toda la producción escrita en torno a la gramática latina sirvió de base para la escolarización del latín (y en el futuro para la de las lenguas vernáculas). La disciplina base de la enseñanza medieval era la gramática, entendida como la lengua latina por excelencia y sus mecanismos. ${ }^{2}$ Y los gramáticos eran, sin saberlo, diccionaristas. Recuerda Verdelho (1995: 26) que «os dicionários na lexicografia europeia, nascem da ciência gramatical da Idade Média. Foram os gramáticos medievais que inventaram os dicionários, alargando ao léxico o esforço de sistematicidade que vinha caracterizando a elaboração gramatical desde a antiguidade». Ese excesivo valor dado a las palabras respondía a la tradición secular de la escritura. Como consecuencia de dicha importancia, el diccionario surgió como apoyo o complemento de los tratados gramaticales. Y en ese clima se publicaron los grandes léxicos medievales.

El paso definitivo del léxico o vocabulario hacia el diccionario se produjo cuando se enfrentaron dos vulgares o el latín con una lengua vulgar. Nos dice Marello (1989: 10) que en los últimos glosarios-vocabularios aparecidos, la lengua vulgar aún tiene un papel instrumental, «un discorso diverso meritano invece le opere lessicografiche che affiancano due volgari e quelle volgare-latino, perchè in esse i volgari diventano finalmente oggetto di confronto e studio diretto. Il fatto è evidente sopratutto nelle opere che affiancano due volgari».

Ya en el Renacimiento, el progreso constante de las lenguas vulgares provocó un nuevo planteamiento en la pedagogía del latín: debía conservarse la lengua culta por excelencia frente a los romances. Y los autores que mostraron esa nueva pedagogía en sus diccionarios fueron Antonio de Nebrija (1492 y 1495), Ambrogio Calepino (1502) y Robert Estienne (1528-1543). En definitiva, y como recuerda Verdelho (1999-2000: 126), «a lexicografia bilingüe e monolingue dos vernáculos europeus desenvolveu-se a partir destes dicionários, aproveitando-os para o agenciamento e ordenação alfabética das respectivas nomenclaturas, e adoptando os seus recursos metalexicográficos, desde as soluções técnicas para a disposição tipográfica, até a elaboração dos artigos, as definições, as citações, etc.».

${ }^{2}$ Léase lo que dice Duby (1977: 34) a propósito de la educación del Medievo: «La enseñanza se basaba en un estudio de las palabras latinas, de su significado, de su disposición: en síntesis, en un léxico y una gramática. De las siete vías del conocimiento, según las cuales los pedagogos de la baja Antigüedad habían dispuesto las etapas de la instrucción escolar, de las siete "artes liberales", los maestros del siglo XI sólo cultivaron verdaderamente la primera, la más elemental, que consistía en una iniciación al lenguaje de la Vulgata». 


\section{EL LATÍN... Y EL PORTUGUÉS}

La lexicografía europea comienza una nueva andadura. Nacen las grandes obras lexicográficas bilingües en un primer estadio latín/lengua vernácula (véase Codoñer, 1989: 25-30) y posteriormente las monolingües. Para el caso portugués, hasta que eso suceda, siete fueron los principales bilingües latín-portugués que se utilizaron en el país vecino desde el siglo XVI hasta el XVIII, siempre al servicio del aprendizaje del latín. Solo en torno a 1770 el marqués de Pombal impuso la obligatoriedad del idioma portugués en las escuelas.

Cabe mencionar que el repertorio de base lexicográfica más antiguo que se conoce en lengua portuguesa es un manuscrito encontrado en el monasterio de Alcobaça ${ }^{3}$ datado del siglo XIV y consiste en una lista de verbos latinos con sus correspondencias portuguesas.

Durante los siglos XVI y XVII ${ }^{4}$ surgen las figuras esenciales de Jerónimo Cardoso, Agostinho Barbosa y Bento Pereira.

Jerónimo Cardoso está considerado el primer lexicógrafo del portugués. El primer diccionario luso, el Dictionarium latinolusitanicum \& vice versa lusitano latinum data de 1569 (1570). Para ilustrar ciertas palabras latinas, Cardoso introdujo ejemplos extraídos de los Adagios de Erasmo de Rotterdam, ejemplos dados en latín con una traducción portuguesa y un posterior comentario en esta misma lengua. Sobre las fuentes en las que se basó Cardoso, nos dice Bajo Pérez (2000: 71-72) al hablar de Nebrija que «la importancia lexicográfica de la obra de Nebrija se aprecia todavía mejor en el hecho de que tanto el Lexicón como el Vocabulario sirvieron de 'plantilla' — si podemos hablar así- para la creación de nuevas obras bilingües: [...] Jerónimo Cardoso publicó en 1569 el Dictionarium Latino Lusitanicum (diccionario latino-luso y lusolatino)», a lo que añade Paul Teyssier (1988: 213), «Cardoso utiliza uma 'metalinguagem' que é interessante analisar para determinar o lugar ocupado por ele no conjunto da lexicografia europeia. Digamos desde já que essa 'metalinguagem' lexicográfica foi tirada de Nebrija». Pero no solo el metalenguaje, recordemos que entre 1580 y 1640 reinaron en Portugal tres monarcas españoles Felipe II, Felipe III y Felipe IV, hecho que provocó una época de bilingüismo en las clases cultas, y Cardoso, inmerso en ese momento histórico, tomó como base en su trabajo los diccionarios de Nebrija.

En 1611 se imprimió el Dictionarium Lusitanicolatinum de Agostinho Barbosa (véase Mendes de Almeida 1965), más copioso que el de Cardoso. El padre Bento Pereira publicó en 1647 el Thesouro da lingoa portuguesa, obra que recoge todo el léxico de Cardoso y Barbosa, pero ampliado (véanse Mendes de Almeida, 1967 y Verdelho, 1993).

3 Está en la Biblioteca Nacional de Lisboa; código CDIV/286. Si se quiere tener más información puede consultarse Leite de Vasconcelos (1932, IV: 257).

${ }^{4}$ En estas centurias se fue consolidando la tradición gramatical para la lengua portuguesa: destacan Fernão de Oliveira, João de Barros, Duarte Nunes de Leão, Pêro de Magalhães Gândavo y Jerónimo Cardoso, que escribieron gramáticas portuguesas a imagen y semejanza de las latinas. 
En Coimbra aparece la obra colosal de Raphael Bluteau, el Vocabulario portuguez e latino, entre los años 1712 y 1721; posteriormente, entre 1727-1728, el Suplemento a su obra y en 1716 apareció el Indiculo Universal de António Franco, obra que en principio era latín-francés hecha por Francisco Pomey y posteriormente adaptada al portugués, siendo latín-portugués por Franco (véase Ayala Castro, 1996).

La sapiencia de Bluteau presidió en 1755 el Diccionario portuguez e latino de Carlos Folqman, y en 1762 Pedro José da Fonseca escribió el Parvum lexicon latinum Lusitana (véase Mendes de Almeida, 1969).

\section{PRIMERos DiCCIONARIOS BILINGÜES PORTUGUESES CON UNA LENGUA VIVA}

Si nos atenemos a lo que afirma Ettinger (1989-1991: 3.020-3.030), la lexicografía bilingüe cuya combinación reúne el portugués con lenguas extra-europeas fue importante durante el siglo XVII: gran cantidad de glosarios con lenguas asiáticas así lo demuestran. Por lo que se refiere a la combinación portugués-lenguas europeas, no aparece hasta los siglos XVIII-XIX, y en el caso de las lenguas eslavas y escandinavas no se da hasta el XX.

Esta tardía aparición de la lexicografía bilingüe portugués-lengua europea puede haberse debido a la extrema importancia que el latín tenía como lengua de cultura en Portugal (acción de la Contrarreforma). ${ }^{5}$ No obstante, el colonialismo propició transacciones comerciales por todo el globo terráqueo, transacciones que se realizaban utilizando lenguas vivas. Recordemos que España, Portugal, Inglaterra, Holanda y Francia dominaban el panorama colonial mundial. Además de las relaciones portuguesas con países europeos donde habían emigrado judíos en la época de la expulsión peninsular.

Trece son los diccionarios que por primera vez enfrentan portugués con otra lengua que no sea el latín desde el siglo XVII hasta el XIX. Por orden cronológico se verán la lengua tupí, el japonés, el hebreo, el inglés, el holandés, el bengalí, el francés, el kimbundu (lengua de Angola) juntamente con una lengua del Congo, el alemán, el chino, el bugre (lengua amazónica), el italiano y el español: un Vocabulario da lingua brasílica (se trata de un manuscrito de 1621); en 1603 apareció en Nagasaki un Vocabulario da Língua do Japão. Com a declaração em português feita por alguns padres e irmãos da Companhia de Jesus, organizado por el misionero João Rodrigues; fechado en 1683, el Vocabulario da lingua Portuguesa explicado em Hebraico, publicado en Amsterdam y escrito por Selomoh de Oliveyra; ya en el siglo XVIII, tenemos A Compleat Account of the Portugueze Language. Being a Copious Dictionary of English with Portugueze and Portugueze with English publicado en Londres en 1701 y escrito por A. J. London; entre 1714 y 1718 encontramos en Amsterdam el Tesouro dos vocábulos das duas linguas portugueza e belgica / wordenschat der twee taalen portugeesch en nederduitsch de Abraham Alewyn y Johannes Collé; en 1743, escrito por Manuel da Assumpção, salió a la venta en Lisboa el Vocabulario em lingua bengala e português; los

${ }^{5}$ Léase Vázquez (2008), donde se especifica la cuestión. 
dos siguientes diccionarios forman un bloque, en 1758 apareció en Lisboa el Nouveau dictionnaire des langues françoise et portugaise de Joseph Marques y en 1764 el Novo Diccionario das linguas portugueza, e francesa del mismo autor; en 1805, Lisboa asistió al nacimiento de la Colecção de observações gramaticais sobre a língua bunda ou angolense, a que adjunta dicionário abreviado da língua conguesa, ao qual acresce uma quarta coluna que contém os termos da língua bunda, idênticos ou semelhantes a língua conguesa de Bernardo Maria da Cannecatim; de 1811 es el Novo Diccionario portuguez-alemão e alemão-portuguez de João Daniel Wagener; entre 1831 y 1833 se publicó en Macao el Dicionário Português-China / China-Português, no estilo vulgar mandarim, e clássico geral de Joaquim Afonso Gonçalves; en 1852 un Vocabulário da língua Bucre apareció en Rio de Janeiro; durante el bienio de 1853-1854 salió de los talleres el Diccionario italiano-portuguez e portugués-italiano de Antonio Bordo y finalmente, en 1864, el Diccionario español-portugués de Manuel do Canto e Castro Mascarenhas Valdez.

En relación a los diccionarios multilingües, en los que siempre aparecía el latín como lengua puente entre idiomas todavía no enfrentados en un diccionario bilingüe, cabe decir que proliferaron mucho por toda Europa hasta inicios del siglo XIX. Hemos documentado once obras de estas características en las que la lengua portuguesa se incluye: el siglo XVI ve la publicación de una obra de carácter médico, el In Discoridis Anazarbei de medica materia de Amatus Lusitanus (o Amato Lusitano, pseudónimo de João Rodrigues de Castelo Branco; véanse Correia, 1968 y Lemos, 1907), fechado en 1553; de 1595 es el Dictionarium Latino-Lusitanicum ac Japonicum, compuesto por los jesuitas sobre la base del diccionario de Calepino.

Como ya se ha insinuado, la eclosión de gran parte de este tipo de diccionarios se debió a las necesidades de los viajeros y comerciantes, necesidades generadas por los grandes descubrimientos marítimos de los siglos XV y XVI.

En el año de 1617 se publicó en Londres The Guide into the Tongues, elaborado por John Minsheu y que contiene once lenguas; en 1621 se imprimió en Lisboa el Raizes da lingua letina mostradas em hum tratado, e diccionario, confeccionado por Amaro Reboredo también a partir del Calepino (es la primera vez que en el famoso diccionario multilingüe aparece la lengua portuguesa); el año 1623 vio la aparición del Porta de Linguas ou modo muito accomodado para as entender, publicado primeiro com a tradução Espanhola. Agora acrescentada a Portuguesa com numeros interliniaes... com as raizes da Latina mostradas em hum compendio do Calepino... e ensinar brevemente, e para os estrangeiros que desejão a Portuguesa e a Espanhola, de Amaro Reboredo; en 1631 apareció el conocido como Colloquia, et dictionariolum octo linguarum: latinae, gallicae, belgicae, teutonicae, hispanicae, italicae, anglicae, portugallicae de autor ignoto (se publicó en Amsterdam y el portugués se contempla entre ocho lenguas); en 1634 apareció el Prosodia in vocabularium trilingue, Latinum, Lusitanicum, \& Hispanicum de Bento Pereira; de 1794 data el Diccionario Portuguez-Francez-eLatino de Joaquim José da Costa e Sá, impreso en Lisboa; de 1800 es A Marine Pocket-Dictionary, of the Italian, Spanish, Portuguese, and Germanic Languages, with An English-French, and French-English Index de Henry Neuman; de 1801 es un Lexicon nosologicum polyglotton de Philippo Andrea Nemnich aparecido en Alemania, que 
trata entre las diversas lenguas la portuguesa, y de 1804 el Diccionario da lingua bunda ou angolense, explicada na portugueza, e latina escrito por Bernardo Maria da Cannecatim.

De entre las obras bilingües, conviene retomar el diccionario de Raphael Bluteau (véase Mendes de Almeida, 1969b), y lo hacemos porque su Vocabulario portuguez e latino (1712) está considerado como precursor de los grandes diccionarios monolingües del portugués en los siglos XIX y XX. El Vocabulario que escribió tiene ocho volúmenes e incluye infinidad de proverbios. Se publicó entre 1712 y 1721; entre 1727 y 1728 aparecieron dos volúmenes más de suplemento que contenían sinónimos y fraseología, además de un vocabulario español-portugués. Aunque se trata de un diccionario bilingüe, la parte portuguesa está muy elaborada y por sí sola podría formar un diccionario monolingüe, la parte latina es mínima. Fue la primera tentativa meritoria de hacer un diccionario luso.

\section{DiCCIONARIOS MONOLINGÜES PORTUGUESES}

Durante el siglo XVIII asistimos a la aparición de los primeros diccionarios monolingües de la lengua portuguesa. Los tres primeros son de poca importancia: en 1765 se publicó en Lisboa el Diccionario Poetico de Cândido Lusitano (pseudónimo de Francisco José Freire; véase Verdelho 1983); se trata de una obra al servicio de la poesía. En 1781 apareció el Diccionario exegetico, de autoría desconocida; también orientado hacia la práctica retórica, dos años después, el Diccionario da língua Portuguesa: em que se acharão dobradas palavras do que traz Bluteau, e todos os mais diccionaristas juntos, de Bernardo de Lima e Melo Bacelar (este diccionario será el primero que utilice el sintagma 'da lingua portuguesa').

Como se observa, siempre estaba presente la figura de Bluteau, pero su diccionario, con ser el mejor era poco funcional, y a tal efecto, ya en 1747 el gramático J. Verney sugería que algún hombre docto debería reducir a un tomo general el Vocabulario. Esa figura fue António de Morais Silva, considerado el gran renovador y padre de la lexicografía portuguesa moderna, que lo redujo a dos volúmenes en 1789 bajo el título Diccionario da lingua portugueza. Despojó el diccionario de toda la información enciclopédica que le pareció superflua, de citas innecesarias, de lenguaje estereotipado y utilizó una metodología totalmente nueva.

La Academia Real das Sciencias publicó el Diccionario da Lingoa portugueza en 1793 (véase Casteleiro, 1936). Consta de un único volumen y desgraciadamente solo trata la letra 'a' (llega hasta la voz azurrar). Las expectativas eran las de la superación del Vocabulario de Bluteau.

Tenemos a continuación el Elucidario das palavras de Frei Joaquim de Santa Rosa de Viterbo, publicado en Lisboa entre 1798 y $1799 .{ }^{6}$ Esta obra fue el único diccionario

\footnotetext{
${ }^{6}$ En 1825 se resumió bajo el título Diccionario portatil das palavras, termos e frazes que em Portugal se usárão e que hoje regularmente se ignórão: resumido, correcto e accondicionado.
} 
de términos del portugués antiguo hasta la reciente publicación en 1992 del Pequeño dicionário do portugués medieval de Batista de Carvalho y y Zenóbia Collares Moreira Cunha, autora a su vez del más reciente Dicionário da Língua Portuguesa Arcaica (2005). Se hacía necesaria esta publicación, ya que como afirmó Michaëlis de Vasconcelos (1945: 275), «o Elucidário de Viterbo é uma contribuição preciosa, insubstituível pelas citações, tiradas de documentos públicos, em parte perdidos. Mas ainda assim é muito pobre, porque ele não podia no seu tempo aproveitar nenhum dos principais monumentos literários da época galego-portuguesa».

Ya en el siglo XIX, la producción lexicográfica monolingüe fue abundante sin «atingir um nível de qualidade e quantidade comparável ao de outras línguas europeias. Numa apreciação global, pode caracterizar-se pelos seguintes aspectos: 1) presença tutelar do dicionário de Morais Silva; 2) divulgação do dicionário de língua; 3 ) aparecimento de alguns grandes dicionários portugueses; 4) escassa renovação teórica» (Verdelho, 1994: 679).

El primer diccionario del nuevo siglo vio la luz en Lisboa y se desconoce su autor o autores. Se trata del Novo Diccionario da Lingua Portugueza, que data del año 1806.

La aludida presencia tutelar de Morais Silva nos obliga a centrarnos en él. La segunda edición de su Diccionario da lingua portuguesa, de 1813, está considerada su obra definitiva. En ediciones posteriores, ya editadas por otros lexicógrafos nada se añade a lo establecido en la segunda y en algunos casos como en la décima de 1949, se aparta de las directrices establecidas por él en su obra primitiva. Apunta Verdelho (1994: 677) que «é uma obra muito diferente da de Bluteau na sua concepção, nos seus objectivos, no tratamento do 'corpus' e até na própria fundamentação lexicográfica. Estamos perante o primeiro dicionário moderno da lexicografía portuguesa». No utilizó Morais solamente la obra de Bluteau, también empleó el único diccionario de la Academia Real das Sciencias. En definitiva, elaboró una obra valiosa, rica en documentación histórica y según los criterios lexicográficos vigentes en Europa.

En 1818, la Imprensa Régia de Lisboa publicó el Diccionario Geral da Lingoa portugueza de algibeira (y su Supplemento en 1821). Posteriormente, en 1824, apareció en la capital de Portugal el Ensaio sobre alguns synonymos da Lingua Portugueza de Francisco de São Luís.

En la década de los años treinta, apareció en escena un lexicógrafo que publicó diversos diccionarios hasta los años setenta, José da Fonseca. Publicó en París en 1829 el Novo Diccionario da Lingua Portugueza, al año siguiente, también en París, un Diccionario de Synonimos Portuguezes, y en 1833, también en la capital gala, el Novo diccionario da lingua portugueza seguido de um diccionario completo dos synonymos portuguezes.

En el año 1836, se imprimió en París el Novo Diccionario crítico e etymologico da lingua portuguesa de Francisco Solano Constâncio (véase Silbert, 1950), diccionario que ha conocido numerosas ediciones. Dice Verdelho que «o dicionarista revela um bom conhecimento da lexicografia europeia do tempo (a própria designação de 'etimologico' começa a aparecer em dicionários franceses da década de 30). [...] Constâncio marca, e de um modo geral no respeitante ao estudo da formação das palavras, uma 
apreciada inovação na história da lexicografia portuguesa» (1994: 680). Cabe decir que es a partir del siglo XIX cuando aparecen los diccionarios etimológicos del portugués.

En 1844 bajo la autoría de Uma Sociedade de Litteratos se publicó el Diccionario Universal da Lingua Portugueza, uno de los primeros del nuevo género híbrido de los diccionarios enciclopédicos.

Los tres diccionarios franceses de Fonseca $(1829,1830,1833)$, fueron recopilados por Roquete en 1848 en una gran obra, el Diccionario da Lingua Portuguesa de José da Fonseca, feito inteiramente de novo e consideravelmente augmentado; fue la obra más divulgada de la lexicografía portuguesa parisina, generalizando el uso del diccionario en la escuela. En el mismo año, junto a José da Fonseca, publicó en la capital francesa el Diccionario dos Synonymos, Poetico e de Epithetos da Lingua Portugueza.

Hacia la mitad del siglo XIX apareció el Novo Diccionario da Lingua Portugueza de Eduardo Augusto de Faria.

Los diccionarios de la segunda mitad del siglo XIX mostraban la preocupación existente en Portugal acerca de la discusión ortográfica y de la actualización de los estudios filológicos. Son de valor desigual; sin embargo, puede decirse que llenan el vacío académico, ya que la Real Academia das Sciencias no completó su obra.

Como se habrá observado, muchos de estos diccionarios aparecieron en Francia; el hecho de que la actividad lexicográfica se trasladase a París implica fuerte dependencia e influencia de los modelos franceses. En París surgieron los modelos definitivos de diccionarios prácticos, siendo los mejores los de Fonseca / Roquete y Constâncio. Seco (1987) afirma que la lexicografía española del XIX que se hizo en París correspondía a una visión comercial de los editores franceses para proveer de material a las recientes repúblicas hispanoamericanas. Esos editores hicieron lo propio para la lexicografía portuguesa teniendo como mercado a la gran república de Brasil. Intervino el hecho de que la lexicografía francesa imprimía una nueva metodología, moderna y que influyó en todos los diccionarios europeos.

De esa época (1853) es el Vocabulário brasileiro para servir de complemento aos dicionários da língua portuguesa, de Brás da Costa Rubim. En este punto hemos de hablar de Brasil: los brasileñismos iban siendo poco a poco incluidos en los diccionarios, siendo Morais uno de los primeros lexicógrafos que anotaba las voces brasileñas con su procedencia. Junto al viejo léxico de Portugal se registran las nuevas voces de Brasil. ${ }^{8}$ No será hasta la aparición de la obra de Caldas Aulete en el XX, cuando un diccionario de lengua portuguesa incluya el léxico común y diferencial de los dos países sin especificar en el título si se trata de portugués de Portugal o de Brasil. ${ }^{9}$

\footnotetext{
${ }^{7}$ Aún publicaron en 1852 en París el Diccionario da lingua portugueza, feito inteiramente de novo e consideravelmente augmentado y en 1863 el Diccionario de synonymos da lingua portuguesa.

${ }^{8}$ En ese sentido, en 1832 era publicado un Diccionario brasileiro da língua portuguesa, escrito por Luís Maria da Silva Pinto.

${ }^{9}$ Un ejemplo de diccionario editado en Brasil con esa preocupación es el Dicionário de vocábulos brasileiros, de Enrique Pedro Carlos de Beaurepair-Rohan (1889).
} 
En el mismo año de 1853 se publica en Lisboa un Diccionario Portatil Portuguez. Del mismo estilo, Miguel Martins Dantas vio publicado en 1858 en París su Novo Diccionario Portatil da Lingua Portugueza. En 1860, José Maria de Almeida e Araujo Correia de Lacerda asistió a la publicación en Lisboa de su Novissimo diccionario da lingua portugueza com reflexões criticas. Entre 1871 y 1874 vio la luz en Oporto el segundo compendio lexicográfico cuyo título contenía la palabra 'thesouro'; se trata del Grande diccionario Portuguez ou thesouro da lingua portuguesa de Frei Domingos Luís Vieira. En 1875, António Joaquim de Macedo Soares vio publicado en Rio de Janeiro su Diccionario brazileiro da lingua portugueza.

Y por fin, en 1881, surgió el diccionario más innovador y que se considera uno de los más divulgados en la actualidad: el Diccionario contemporaneo da lingua portugueza de Francisco Caldas Aulete, que ha conocido desde su aparición constantes reediciones y ampliaciones. En 1882 apareció en Lisboa el Diccionario Universal Portuguez Illustrado, redactado 'pelos principaes escriptores', de Henrique Zeferino de Albuquerque. De 1884 data el Diccionario da Lingua Portugueza Etymologico, Prosodico e Orthographico.

Un año más tarde, en 1885, se publicó en Lisboa Os Synonymos e Homonymos da Lingua Portuguesa de João Félix Pereira. Y en 1889, Levindo Castro de La Fayette vio la impresión de su Novo Vocabulario Universal da Lingua Portugueza en París. En 1890 salió a la venta el Dicionário Manual Etimológico da Língua Portuguesa de Adolfo Coelho. De Francisco de Almeida apareció en Lisboa, en 1891, el Novo Diccionario Universal Portuguez y, al año siguiente, Francisco de Almeida y Henrique Brunswick dieron a la imprenta el Diccionario Illustrado da Lingua Portugueza; ya en 1899, Brunswick publicó su Diccionario de Synónymos da Lingua Portugueza. Finalmente, en fecha imprecisa, pero en el último decenio del XIX, se publicó a la vez en Rio de Janeiro y en París el Diccionario encyclopedico da lingua portuguesa de Simões da Fonseca.

Durante el siglo XX se fundaron diferentes empresas en Portugal que hoy en día dominan el ámbito editorial de los diccionarios. Diversas razones pueden apuntar a esclarecer este hecho. Una de ellas quizás sea la inactividad — hasta el año 2001- de la Academia das Ciências de Lisboa en el campo lexicográfico. Otra, puede ser el acceso masivo de la población a la educación. ${ }^{10}$

En las líneas siguientes intentaremos encuadrar la producción lexicográfica portuguesa a través de dos vías: los diccionarios de autor, centrándonos en los más divulgados, y la aportación de las editoriales (Porto, Texto, Lello, Bertrand, Primberam, etc.). Los diccionarios más divulgados siguen siendo de autor y en algunos casos obras heredadas del siglo precedente. Algunos de los lexicógrafos que a continuación se detallan

\footnotetext{
${ }^{10}$ Muchos docentes se encontraban con una falta considerable de material instructor. Se agruparon y fundaron pequeñas editoriales para paliar esa falta; alguna de ellas, como es el caso de la Porto Editora, es en la actualidad la más afamada en ese campo. Por otro lado, la liberalización económica y cultural hizo que las empresas tipográficas viesen un mercado prometedor en el mundo de la cultura en general $\mathrm{y}$ en el de la enseñanza en particular.
} 
vieron publicados sus diccionarios en las grandes editoriales que en algunos casos publicaron compendios lexicográficos sin autoría expresa y han contribuido a la fama y crecimiento de la editorial en cuestión.

Los diccionarios de la primera mitad de siglo contienen en su mayoría alusiones a la ortografía en el título, ya que entre 1885 y 1943 se fue conformando la norma ortográfica actual. Excepto tres obras aparecidas durante el siglo anterior, Brasil inicia su despegue en la producción de diccionarios en el veinte. En esta órbita, apareció el primer diccionario portugués monolingüe del siglo XX y en la actualidad uno de los más manejados, se trata del Novo diccionario da língua portuguesa (1899) de António Cândido de Figueiredo. ${ }^{11}$ Entre 1904 y 1905 se publicó en Lisboa el Diccionario da Lingua Portugueza (Prosodico e orthographico) de Fernando Mendes.

Tras las Bases ortográficas de 1885, en 1911 se promulgaron las de la reforma ortográfica simplificada de la lengua portuguesa, cuyo principal impulsor fue el fonetista Aniceto dos Reis Gonçalves Viana, quien vio impreso en 1909 el Vocabulário Ortográfico e Ortoépico da Língua Portuguesa (conocido desde 1913 como Vocabulário ortográfico e remissivo. ${ }^{12} \mathrm{Su}$ obra se tornó de consulta indispensable hasta el acuerdo ortográfico luso-brasileño de 1943.

En 1910 apareció en Lisboa el Diccionario da Antiga Linguagem Portugueza de Henrique Brunswick. En 1912 se publicaron en Lisboa las siguientes obras: el Diccionario Etymologico, Prosodico e Orthographico da Lingua Portugueza de José Timóteo da Silva Bastos, y el Vocabulario ortografico da lingua portuguesa de Francisco Augusto Xavier Rodrigues. Un año más tarde se publicó en Oporto $O$ novo dicionário português de José Pestana y J. A. Pereira.

De acuerdo con la nueva ortografía de 1913, apareció publicado en 1917 el $\mathrm{Di}$ cionário popular da língua portuguesa de Albano de Sousa. En 1921 se publicó en Oporto el Dicionário popular para Portugal e Brasil de Augusto Moreno ${ }^{13}$. En 1923 apareció en Coimbra el Diccionario de Synonimos da Lingua Portuguesa, de José da Silva Bandeira y en 1931 salió publicado en Oporto el Moderno dicionário da língua portuguesa de Francisco Torrinha; ${ }^{14}$ conoció bastante éxito, dado que la sexta edición es de 1937.

Una de las figuras importantes de la lexicografía en lengua portuguesa realizada en Brasil es Antenor Nascentes. Su mayor obra fue el Dicionário etimológico da língua

${ }^{11}$ La obra ha conocido reiteradas ediciones desde que apareció; la quinta, de 1940, fue ampliamente aumentada. Con posterioridad, las diferentes editoriales han ido haciendo sus versiones de este diccionario, en algunos casos mejorándolo, pero siempre manteniendo el espíritu purista del autor.

Otras obras de Cândido de Figueiredo son el Novo diccionario da Lingua Portuguesa (1911), el Pequeno diccionario da Lingua Portuguesa (1913) y el Pequeno Dicionário da Língua Portuguesa (1924).

${ }^{12}$ Resulta de interés Viana (1904).

${ }^{13}$ Durante los años treinta escribió el Dicionario elementar da língua portuguesa (1934) y el Dicionario complementar da língua portuguesa (1936), que se han ido reeditando y actualizando hasta prácticamente finales de los 70 .

${ }^{14}$ En 1942 publicó Novo dicionário da língua portuguesa: para os estudantes e para o povo. 
portuguesa (1932-1952); ${ }^{15}$ consta de dos volúmenes, el primero dedicado al léxico del portugués (con introducción de Meyer-Lübke) y el segundo a los nombres propios.

Corría el año de 1935 cuando se publicó el Dicionário geral da língua portuguesa de Carlos Alberto Correa, y el año 1936 cuando apareció el Novíssimo Dicionário Prosódico e Ortográfico da Língua Portuguesa de José C. Antunes Coimbra. El mismo año se publicó el Novo dicionário popular da lingua portuguesa de Bernardino Augusto Ligorne. En 1938, ve la luz el Dicionário de língua portuguesa para uso das escolas de Agostinho Celso Azevedo de Campos.

Aurélio Buarque de Holanda Ferreira está considerado uno de los lexicógrafos más insignes del siglo XX (junto a Cândido de Figueiredo y Antônio Houaiss). Inició su labor lexicográfica en los años treinta. En 1941 se publicó el Pequeno Dicionário Brasileiro da Língua Portuguesa en el que colaboró.

En 1945 apareció en Brasil un Dicionário prático da língua nacional de José Mesquita Carvalho. Entre 1948 y 1958 salió a la venta el Dicionário Geral e Analógico da Língua Portuguesa de Artur Bivar y en 1949, basándose en la obra de Morais, José Pedro Machado editó en Lisboa el Grande dicionário da língua portuguesa de António de Morais da Silva. El año 1949 asistió a la aparición en Lisboa del Dicionário de Sinónimos da Língua Portuguesa de Alfredo Leite Pereira de Mello, y en 1950 se publicó en Rio de Janeiro el Dicionário de Sinónimos e Locuções da Língua Portuguesa de Agenor Costa.

De 1952 es el Dicionário etimológico da língua portuguesa: com a mais antiga documentação escrita e conhecida de muitos dos vocábulos estudados de José Pedro Machado. ${ }^{16}$ En 1954 se comercializó en Rio de Janeiro la segunda edición del Dicionário contemporâneo da língua portuguesa com um breve estudo sôbre a origem e evolução da língua portuguesa, sua expansão no Brasil, e uma exposição da pronúncia normal brasileira de Francisco Caldas Aulete, bajo la dirección de Hamílcar de Garcia y Antenor Nascentes. $^{17}$

Fernando José da Silva escribió el Dicionário da língua portuguesa: ortoépico, ortográfico, etimológico e arcaico publicado en 1956 en Oporto. En 1957 encontramos el Novo dicionário etimológico da lingua portuguesa de Rodrigo Fontinha y en 1961 salió a la venta el Novo diccionario compacto da língua portuguesa, una versión reducida a cinco volúmenes de la obra que José Pedro Machado había hecho en 1949 sobre el

${ }^{15}$ En 1949 publicó el Dicionário básico do português do Brasil.

${ }^{16}$ Véase la reseña de Joseph Piel (1960). Otros diccionarios de Machado son el Dicionário da Língua Portuguesa (cuyo primer volumen apareció en 1951, mientras el séptimo y último se demoró hasta 1971), el Dicionário da língua portuguesa (1960), el Grande Dicionário da Língua Portuguesa (1981) y el Dicionário onomástico etimológico da língua portuguesa (1984).

${ }^{17}$ Hamílcar de Garcia y Antenor Nascentes han sido figuras capitales en la actualización y mejora reiterada del diccionario Aulete, de tal modo que la quinta edición (Dicionário contemporâneo da língua portuguesa, 1964) y, especialmente su reedición mejorada se considera como la mejor (Dicionário contemporâneo da língua portuguesa, $5^{\mathrm{a}}$ ed. rev. actual. e aumentada [...] por Hamílcar de Garcia, 1986, Dicionário contemporâneo da língua portuguesa, com Antenor Nascentes, $5^{\mathrm{a}}$ ed. rev. e aum. por Hamílcar de Garcia, 1987). 
diccionario de Morais (novena edición en 1999). Entre 1961 y 1967, Antenor Nascentes publicó el Dicionário da língua portuguesa de la Academia Brasileira de Letras. La lisboeta editorial Enciclopédia publicó entre 1963 y 1966 el Dicionário geral lusobrasileiro da língua portuguesa coordinado por Afonso Zúquete, y este último año salió de la imprenta el Vocabulário da Língua Portuguesa de Francisco da Luz Rebelo Gonçalves $^{18}$. Y de 1971 data la publicación en Moscú del Dicionário inverso da língua portuguesa de E. M. Wolf.

En 1975 apareció el Novo dicionário da língua portuguesa, de Holanda Ferreira, conocido popularmente como el Aurélio; la segunda edición, de 1986, se considera como la definitiva y la obra maestra de Aurélio Buarque de Holanda Ferreira, ${ }^{19}$ hoy en día en versión actualizada conforme al «Acordo ortográfico» de 1990, que ha entrado en vigor en todos los países lusófonos en 2008.

En 1976 salió de la imprenta el segundo diccionario de la Academia de Ciências de Lisboa, el Dicionário da língua portuguesa; como el anterior, de 1793, solo posee una letra, la A y acaba en la voz azuverte, de origen brasileño y sin uso en Portugal. La empresa, fallida, solo tendrá continuación en la edición del diccionario aparecido en 2001.

En 1979 se publicó en Lisboa $O$ nosso Dicionário de Alfredo Camacho y en 1972, en Rio de Janeiro, el Dicionário etimológico nova fronteira da língua portuguesa de Antônio Geraldo da Cunha. En 1988, también en Brasil, apareció el Grande dicionário etimológico-prosódico da língua portuguesa de Francisco da Silveira Bueno, y ese mismo año, pero en Lisboa, el Dicionário ilustrado da língua portuguesa de Francisco Fernandes. Un año después se comenzó a vender el Dicionário prático ilustrado: novo dicionário enciclopédico Luso-Brasileiro de Jaime Séguier, actualizado en 1996 de acuerdo al «Acordo ortográfico»; parece ser que este diccionario, de carácter enciclopédico, es una adaptación del Petit Larousse al portugués.

Ya en la década de los noventa, se publicaron el Dicionário do português básico de Mário Vilela (1990; véase Vilela 1987), el Grande Dicionário da Língua Portuguesa, Acordo ortográfico da língua portuguesa de José Pedro Machado $(1991)^{20}$ y el Dicionário da língua portuguesa de Dolores Rodríguez Cebral (1996). Fundamentándose en la base de Figueiredo (1899), Rui Guedes escribió en 1996 el Grande dicionário da língua portuguesa, correspondiente a la vigésimo quinta edición edición de la obra de 1899. En 1998 se publicó O meu dicionário da língua portuguesa de Bernardo Barrosa y un año después el Língua portuguesa: dicionário elementar de Aldónio Gomes. Ese mismo año, se publicó en Lisboa una nueva versión del Dicionário da Língua Portuguesa de Francisco Torrinha con el apoyo del Instituto Camões.

${ }^{18}$ Este catedrático de clásicas de la Universidad de Coimbra fue miembro de la Academia de Ciências de Lisboa y dirigió los trabajos del Vocabulário Ortográfico da Língua Portuguesa de 1940 editados por dicha institución. Este trabajo debía ser la base para el diccionario de la Academia, y mucho sospechamos que, ante su falta de actividad, se decidió a publicar él mismo su obra.

${ }^{19}$ Otras obras son Holanda Ferreira (1977) y (1980).

${ }^{20}$ En 1999 el Breve dicionário enciclopédico da língua portuguesa: revisto e actualizado. 
En el siglo XXI, aparecen dos diccionarios muy esperados: el Dicionário da língua portuguesa contemporânea da Academia das Ciências de Lisboa y el Dicionário Houaiss da Língua Portuguesa de Antônio Houaiss, ambos de 2001. ${ }^{21}$ El diccionario de Houaiss dispone ya (2009) de una versión actualizada según el «Acordo ortográfico» de 1990.

En definitiva, las grandes obras lexicográficas portuguesas son deudoras las unas de las otras; como dice Teyssier (1985), Jerónimo Cardoso fue el iniciador, el fundador de la lexicografía portuguesa. Con los mediadores Agostinho Barbosa (1611), Bento Pereira (1634) y Bluteau (1712-1728), una cadena ininterrumpida conduce a Morais (1789), y finalmente a todos los diccionarios modernos de la lengua. Claro está que esa cadena está matizada en algunos casos.

Mención aparte merecen las editoriales que han financiado la publicación de diccionarios de la lengua portuguesa, que hemos ordenado alfabéticamente:

De Alfa Publicações, ubicada en Lisboa, destacamos el Dicionário enciclopédico Alfa de 1990. En 1992 salió el Dicionário enciclopédico de língua portuguesa, basado en las selecciones del Reader's Digest. En 1948 aparecía publicado por la lisboeta editorial Bertrand el Dicionário da língua portuguesa (se trata de la tercera edición del diccionario de Agostinho de Campos editado en 1938); el Círculo de Leitores en Lisboa publicó en 1985 el Lexicoteca: moderno dicionário da língua portuguesa. La editorial Civilização editó el Pequeno dicionário brasileiro da língua portuguesa en São Paulo, el año 1938, y Dom Quixote en Lisboa publicó el Dicionário da língua portuguesa: revisto e actualizado, cuya primera edición es de 1999 (está encuadrado dentro de la colección «Dicionários Dom Quixote», 43).

Fifel, editorial brasileña, sacó a la venta su Dicionário conciso da língua portuguesa en Rio de Janeiro en 1977. Por su parte, Fluminense publicó el Dicionário da língua portuguesa en Lisboa en 1987, en la colección «Dicionários do estudante».

En España, concretamente en Barcelona, Leandro Lara Ed. publicó su Dicionário prático da língua portuguesa en el año 1995.

Lello \& Irmão es una de las editoriales más antiguas de Portugal, ubicada en Oporto. Una de sus obras más antiguas es el Lello popular: novo dicionário ilustrado da

${ }^{21}$ En cuanto al primer diccionario, parece que cubre el déficit lexicográfico que la Academia ha tenido durante dos siglos, sin embargo, ha suscitado opiniones encontradas entre la intelectualidad portuguesa, así como entre el usuario corriente de la obra. Consta de 70.000 entradas; está impreso en dos volúmenes y recoge desde la 'a' a la ' $z$ '.

Por lo que se refiere al Dicionário Houaiss, como ya se le conoce, fue iniciado en 1986 por Antônio Houaiss (Rio de Janeiro, 1915-1999), interrumpido con la muerte de su autor y después proseguido y coordenado por Mauro de Salles Vilar. Reúne un acervo de 280.000 entradas, con registro de regencias, locuciones, dataciones, etimología, sinonimia, antonimia y paronimia.

En palabras del periodista António Valdemar (2000), "pela sua dupla apresentação -impressa e electrónica- e pelo aprofundamento que pretende atingir, tudo faz supor que o Dicionário Geral da Língua Portuguesa deverá colocar a lexicografia da língua portuguesa à altura das línguas mais difundidas modernamente». 
língua portuguesa, con fecha de publicación en $1948 .^{22}$ Lisa, junto a Livros Horizonte, sacó a la venta en São Paulo en 1981 el Lisa: grande dicionário enciclopédico da língua portuguesa. Melhoramentos, de São Paulo, publicó en Brasil el Melhoramentos: dicionário prático da língua portuguesa en 1995, pero sin duda alguna su gran obra es el Michaelis: moderno dicionário da língua portuguesa, de 1998. Mirador Internacional vio la aparición en 1976 del Dicionário brasileiro de língua portuguesa en São Paulo. La Moçambique Editora, una de las pocas africanas, publicó el año 1999 en Maputo el Dicionário universal da língua portuguesa.

Porto Editora $^{23}$ es en la actualidad una de las editoriales más famosas y cuyos diccionarios son los más divulgados en el mercado portugués. No solo en lo que se refiere a la lengua portuguesa en edición monolingüe, sino también en cuanto a la lexicografía bilingüe portugués/otra lengua. Posee diferentes colecciones en los que agrupa sus diccionarios. Los monolingües son los siguientes: bajo la coordinación de Joaquim Costa Almeida y A. Sampaio Melo se publicó en los años cincuenta el Dicionário de português (la primera edición es de 1952); desde 1974, fecha en que apareció la quinta edición, en que pasó a llamarse Dicionário da língua portuguesa, prácticamente cada año conoce sucesivas impresiones y reediciones, aumentadas y corregidas (la actual es de 2010 y se ajusta a la ortografía del 'Acordo ortográfico' de 1990). ${ }^{24}$ De los años ochenta es su Dicionário da língua portuguesa para o ensino básico.

Povo Ed., publicó en 1909 su Diccionario da língua portugueza: etymologico prosodico e orthographico en Lisboa. De 1947 data el Dicionário de sinónimos da língua portuguesa de la Sociedade Independente de Tipografia (Lisboa).

Texto Editora se fundó en Lisboa en 1977, con el objetivo de editar libros didácticos. A partir de 1986 se amplió el mercado hacia publicaciones no estrictamente escolares y desde 1994 ocupa el segundo lugar en el ranking de las editoriales portuguesas.

${ }^{22}$ En 1952 editaron la misma obra revisada con el título siguiente: Lello popular: novo dicionário ilustrado da língua portuguesa: segundo as bases do novo acordo ortográfico entre o Brasil e Portugal. Posteriormente, en 1975, fue publicado el Lello escolar: novo dicionário ilustrado da língua portuguesa, com um epítome de gramática e regras ortográficas, uma lista de locuções latinas e estrangeiras e outra dos principais provérbios. En 1989, el Lexillelo: Novo dicionário da língua portuguesa, en cinco volúmenes, y en 1999, el Novo dicionário Lello: estrutural, estilístico e sintáctico da língua portuguesa.

${ }^{23}$ La editorial se fundó en 1944 y su objetivo era publicar libros escolares y diccionarios de gran calidad. Su fundador, Vasco Teixeira, era profesor universitario y al ver los problemas del mundo de la educación, se decidió junto a un grupo de profesores a iniciar el proyecto.

${ }^{24}$ En 1995, La Porto Editora se asoció con la Priberam Informática, Lda. para la producción de herramientas informáticas para la lengua portuguesa. A este consorcio pertenece la versión digitalizada, aparecida en 1996 del Dicionário da Língua Portuguesa: CD-ROM: optimizado para Windows 95.

En 1995 se publicó el Dicionário básico da língua portuguesa, y con Priberam se editó el formato electrónico (Dicionário básico da Língua Portuguesa, [Documento electrónico]). En 1998 y 1999 se reeditaron actualizadas. Del mismo año 1995 es el Dicionário multimédia universal da língua portuguesa [Documento electrónico]: CD-ROM para Windows. En 1996 apareció el Dicionário mini da língua portuguesa. Otras publicaciones de Porto y Primberam son los llamados FLIP: Ferramentas para a Língua Portuguesa: corrector ortográfico, dicionário de sinónimos, hifenizador, editor de texto: versão para Microsoft Windows, de 1995, con ediciones actualizadas en 1997, 1999 y 2009. 
Los diccionarios que ha publicado son: Dicionário universal da língua portuguesa: escolar (1995; en 1998 se amplió con una gramática), que en 1999 ofrece la cuarta edición actualizada, que en el año 2000 iba por su sexta edición. En 1999 publicó el Dicionário (da) língua portuguesa y el Dicionário Universal Milénio. Língua Portuguesa, además del Dicionário universal lingua portuguesa: compacto. ${ }^{25}$

\section{A MODO DE CONCLUSIÓN}

La historia de los diccionarios portugueses presenta la siguiente pauta: a) una lexicografía bilingüe con el latín; b) la publicación de obras multilingües con el latín como lengua puente; c) los primeros bilingües con lenguas asiáticas o amerindias, no con lenguas europeas (el portugués no tenía en los siglos XVI y XVII proyección europea, su interés en esos siglos se volcó en la expansión ultramarina y por ello la necesidad de diccionarios bilingües portugués/japonés, portugués/lengua bengala, portugués/tupí...); habrá que esperar prácticamente al siglo XVIII para que el portugués aparezca en diccionarios bilingües junto a las grandes lenguas europeas y d) los primeros monolingües.

El nacimiento de la lexicografía monolingüe lusa es tardía si la comparamos con la de otras lenguas europeas, dado que el latín fue hasta bien entrado el siglo XVIII la lengua de cultura por excelencia en el país vecino. Será a partir de ese siglo cuando la situación de la lexicografía portuguesa se iguale a la de las restantes lenguas.

El siglo XIX supuso un viraje en la historia de los diccionarios, surgiendo los primeros etimológicos, los enciclopédicos y la lexicografía hecha con más rigor según las líneas que venían de Francia.

El siglo XX, con la democratización de la cultura y con la lexicografía como ciencia cada vez más consolidada, propicia en el ámbito lexicográfico que el portugués se vaya colocando a la altura de las demás lenguas. En Portugal, la inexistencia de una Academia de la Lengua al estilo de la española o francesa ha supuesto que sea el uso literario, periodístico y científico el encargado de consolidar la normativa, la fijación del idioma; este hecho ha favorecido que el papel de Brasil sea importantísimo en la lexicografía. La dificultad del consenso entre la ex-colonia con una norma ortográfica ligeramente diferente a Portugal propició que comenzase una labor diccionarística muy rica que en algunos casos ha ensombrecido a la propia metrópoli.

Como colofón, queremos reproducir en estas líneas unas palabras pronunciadas por Mário Vilela en 1986, con ocasión de un Coloquio sobre lexicografía celebrado en Santiago de Compostela, y que, veinte años después, todavía pueden resumir el estado actual de la lexicografía portuguesa. Refiriéndose a los estudios que se realizan en la Universidad de Porto, dijo:

${ }^{25}$ En formato electrónico tenemos $O$ grande dicionário multimédia universal [CD-ROM]: língua portuguesa: dicionário integral + dicionário escolar, de 1996. 
Em Portugal havia uma tradição lexicográfica importante, mas esgotou-se, em parte, no século XIX. Os nossos melhores dicionários actuais continuam ainda a ser os do século XIX: o Dicionário de Morais, o Dicionário de Caldas Aulete e o Dicionário de Cândido de Figueiredo. Os dicionários mais divulgados, o Dicionário da Língua Portuguesa da Porto Editora e o Dicionário de Aurélio (Brasil), são de valor muito desigual [...] (1988: 199).

En la actualidad, debido a la reciente aparición de los diccionarios de la Academia y del Houaiss, pocos estudios existen sobre ellos, no obstante, son obras que han modernizado la lexicografía portuguesa. Del Houaiss se anunció ya en su presentación una edición para Portugal que comenzó su publicación en 2002 y que acabó a lo largo del 2003; es una versión en seis volúmenes editada por el Círculo de Lectores de Lisboa. Y a partir de 2009 empiezan a comercializarse las versiones actualizadas conforme al Acordo ortográfico de 1990, cuya entrada en vigor se fijó en 2008.

\section{BIBLIOGRAFÍA PRIMARIA}

ACAdemia de CiÊnCIAS de Lisboa (1976): Dicionário da língua portuguesa, Lisboa, Imprensa Nacional.

ACAdemia dAS CiÊNCIAS DE LisbOA (2001): Dicionário da língua portuguesa contemporânea, Lisboa, Verbo.

ACAdemia Real Das Sciencias (1793): Diccionario da Lingoa portugueza, Lisboa, Academia.

ACCAdemia della Crusca (1612): Vocabolario degli Accademici della Crusca, Venezia, Giovanni Alberti.

Albuquerque, Henrique Zeferino de (1882): Diccionario Universal Portuguez Illustrado, Lisboa, Typ. do Diccionario Universal Portuguez.

AlEWYN, Abraham y Johannes Collé (1714 y 1718): Tesouro dos vocábulos das duas linguas portugueza e belgica / wordenschat der twee taalen portugeesch en nederduitsch, Amsterdam, Beter Vanden Berge.

AlmeIDA, Francisco de (1891): Novo Diccionario Universal Portuguez, Lisboa, Cardoso. - y Henrique BRUnswick (1892): Diccionario Illustrado da Lingua Portugueza, Lisboa, Editora Fco. Pastor.

Almeida, Joaquim Costa y A. SAmpaio Melo (1952): Dicionário de português, Oporto, Porto Ed.

Amatus Lusitanus [João Rodrigues de Castelo Branco] (1553): In Discoridis Anazarbei de medica materia, Venecia, Scoto. 
ASSUMPÇÃO, Manuel da (1743): Vocabulario em lingua bengala e português, Lisboa, Officina de Fco. da Silva.

Aulete, Francisco Júlio Caldas (1881): Diccionario contemporaneo da lingua portuguesa, Lisboa, Imprensa Nacional.

(1954): Dicionário contemporâneo da língua portuguesa com um breve estudo sôbre a origem e evolução da língua portuguesa, sua expan-são no Brasil, e uma exposição da pronúncia normal brasileira, Rio de Janeiro, Delta.

- (1954): Dicionário contemporâneo da língua portuguesa com um breve estudo sôbre a origem e evolução da língua portuguesa, sua expansão no Brasil, e uma exposição da pronúncia normal brasileira, Hamílcar de Garcia y Antenor Nascentes, dir., Rio de Janeiro, Ed. Delta.

(1964): Dicionário contemporâneo da língua portuguesa, Hamílcar de Garcia y Antenor Nascentes, dir., Rio de Janeiro, Editora Delta, $5^{\mathrm{a}}$ ed.

(1986): Dicionário contemporâneo da língua portuguesa, $5^{\mathrm{a}}$ ed. rev. actual. e aumentada [...] por Hamílcar de Garcia, Rio de Janeiro, Delta.

(1987): Dicionário contemporâneo da língua portuguesa, com Antenor Nascentes, $5^{\mathrm{a}}$ ed. rev. e aum. por Hamílcar de Garcia, Rio de Janeiro, Editora Delta.

BACELAR, Bernardo de Lima e Melo (1783): Diccionario da língua Portuguesa: em que se acharão dobradas palavras do que traz Bluteau, e todos os mais diccionaristas juntos, Lisboa, Bulhoens.

BAndeIRA, José da Silva (1923): Diccionario de Synonimos da Lingua Portuguesa, Coimbra, Tip. Gráfica Conimbricense.

Barbosa, Agostinho (1611): Dictionarium Lusitanicolatinum, Braga, Frutuosi Laurentij.

BARrosA, Bernardo (1998): O meu dicionário da língua portuguesa, Maia, Nova Gaia.

Bastos, José Timóteo da Silva (1912): Diccionario Etymologico, Prosodico e Orthographico da Lingua Portugueza, Lisboa, Pereira.

Beaurepair-Rohan, Enrique Pedro Carlos de (1889): Dicionário de vocábulos brasileiros, Rio de Janeiro, Imprensa Nacional.

BIVAR, Arturo (1948-1958): Dicionário Geral e Analógico da Língua Portuguesa, Porto, Edições Ouro.

Bluteau, Raphael (1712-1721): Vocabulario portuguez e latino, Coimbra, Companhia de Jesus.

(1727-1728): Suplemento, Lisboa, Patriarcal Officina de Musica. 
BORDO, Antonio (1853-1854): Diccionario italiano-portuguez e portugués-italiano, Rio de Janeiro, Tipográfica Brasiliense.

Brunswick, Henrique (1899): Diccionario de Synónymos da Lingua Portugueza, Lisboa, Pastor.

(1910): Diccionario da Antiga Linguagem Portugueza, Lisboa, Imprensa Lusitana.

CAlepino, Ambrogio (1502): Dictionarium linguae latinae, Reggio, Berthocci.

CAMACHO, Alfredo (1979): O nosso Dicionário, Lisboa, Didáctica ( $\left(1991^{12}\right)$ : O nosso Dicionário, Lisboa, Didáctica

CAmpos, Agostinho Celso Azevedo de (1938): Dicionário de língua portuguesa para uso das escolas, Lisboa, Portugal-Brasil.

(1948): Dicionário de língua portuguesa, Lisboa, Bertrand.

CÂndido Lusitano [Francisco José Freire] (1765): Diccionario Poetico, Lisboa, Ameno.

Cannecatim, Bernardo Maria da (1804): Diccionario da lingua bunda ou angolense, explicada na portugueza, e latina, Lisboa, Imprensa Regia.

(1805): Colecção de observações gramaticais sobre a língua bunda ou angolense, a que adjunta dicionário abreviado da língua conguesa, ao qual acresce uma quarta coluna que contém os termos da língua bunda, idênticos ou semelhantes a língua conguesa, Lisboa, Imprensa Nacional.

CARDoso, Jerónimo (1570): Dictionarium latinolusitanicum \& vice versa lusitano latinum, Coimbra, Joam Barrerius.

Carvalho, Annecildo Batista de y Zenóbia Collares Moreira (1992): Pequeno Dicionário do Português Medieval, Natal, Universidade Federal de Rio Grande do Norte.

CARvalho, José Mesquita de (1945): Dicionário prático da língua nacional, Porto Alegre, Globo.

Coelho, Adolfo (1890): Dicionário Manual Etimológico da Língua Portuguesa, Lisboa, Plantier.

Coimbra, José C. Antunes (1936): Novíssimo Dicionário Prosódico e Ortográfico da Lingua Portuguesa, Lisboa, Franco.

Colloguia, et DiCTIONARIOLUM OCTO Linguarum (1631): Colloquia, et dictionariolum octo linguarum: latinae, gallicae, belgicae, teutonicae, hispanicae, italicae, anglicae, portugallicae, Amsterdam, Cloppenburgium. 
COnStÂncio, Francisco Solano (1836): Novo Diccionario crítico e etymologico da lingua portuguesa, París, Tip. de Casimir.

CORREA, Carlos Alberto (1935): Dicionário geral da língua portuguesa, Lisboa, Império.

Costa, Agenor (1950): Dicionário de Sinónimos e Locuções da Língua Portuguesa, Rio de Janeiro, Imprensa Nacional.

Costa E SÁ, Joaquim José da (1794): Diccionario Portuguez-Francez-e-Latino, Lisboa, Officina de Thaddeo Ferreira.

Covarrubias, Sebastián de (1611): Tesoro de la lengua castellana o española, Madrid, Luis Sánchez.

CunHA, Antônio Geraldo da (1972): Dicionário etimológico nova fronteira da língua portuguesa, Rio de Janeiro, Nova Fronteira.

Dantas, Miguel Martins (1858): Novo Diccionario Portatil da Lingua Portugueza, París, Aillaud/Guillard.

DICCIONARIO DA LÍNGUA PORTUGUEZA: ETYMOLOGICO PROSODICO E ORTHOGRAPHICO (1909):

Diccionario da língua portugueza: etymologico prosodico e orthographico, Lisboa, Povo Ed.

DicCionario da Lingua Portugueza Etymologico (1884): Diccionario da Lingua Portugueza Etymologico, Prosodico e Orthographico, Lisboa, Corazzi.

DiCCIONARIO EXEGETICO (1781): Diccionario exegetico, Lisboa, Imprenta Ameno.

DiCCIONARIO GERAL DA LINGOA PORTUGUEZA (1818): Diccionario Geral da Lingoa portugueza de algibeira, Lisboa, Imprensa Régia.

DicCionario Portatil Portuguez (1853): Diccionario Portatil Portuguez, Lisboa, Souza.

DICIONÁRIO BRASILEIRO DE LÍNGUA PORTUGUESA (1976): Dicionário brasileiro de língua portuguesa, São Paulo, Mirador Internacional Ed.

DICIONÁRIO CONCISO DA LÍNGUA PORTUGUESA (1977): Dicionário conciso da língua portuguesa, Rio de Janeiro, Fifel.

DiCIONÁRIO DA LÍNGUA PORTUGUESA (1974): Dicionário da língua portuguesa, Oporto, Porto Ed, $5^{\mathrm{a}}$ edición.

DicionáRIO DA Língua PORTUGUesa (1987): Dicionário da língua portuguesa, Lisboa, Fluminense.

DiCIONÁRIO (DA) LÍNGUA PORTUGUESA (1999): Dicionário (da) língua portuguesa, Lisboa, Texto Editora. 
DiCIONÁRIO DA LÍNGUA PORTUGUESA PARA O ENSINO BÁSICO (198-): Dicionário da língua portuguesa para o ensino básico, Oporto, Porto Ed.

DiCIONÁRIO DA LÍNGUA PORTUGUESA: REVISTO E ACTUALIZADO (1999): Dicionário da língua portuguesa: revisto e actualizado, Lisboa, Dom Quixote.

DiCIONÁRIO DE SINÓNIMOS DA LÍNGUA PORTUGUESA (1947): Dicionário de sinónimos da língua portuguesa, Lisboa, Sociedade Independente de Tipografia.

DiCIONÁRIO ENCICLOPÉDICO ALFA (1990): Dicionário enciclopédico Alfa, Lisboa, Alfa Publicações.

DiCIONÁRIO ENCICLOPÉDICO DE LÍNGUA PORTUGUESA (1992): Dicionário enciclopédico de língua portuguesa, Lisboa, Selecções do Reader's Digest.

DiCIONÁRIO PRÁTICO DA LÍNGUA PORTUGUESA (1995): Dicionário prático da língua portuguesa, Barcelona, Leandro Lara.

DICIONÁRIO UNIVERSAL DA LÍNGUA PORTUGUESA (1999): Dicionário universal da língua portuguesa, Maputo, Moçambique Editora.

DICIONÁRIO UNIVERSAL DA LÍNGUA PORTUGUESA: ESCOLAR (1995): Dicionário universal da língua portuguesa: escolar, Lisboa, Texto Editora.

DICIONÁRIO UNIVERSAL LÍNGUA PORTUGUESA: COMPACTO (1999): Dicionário universal língua portuguesa: compacto, Lisboa, Texto Editora.

Dicionário Universal Milénio. Língua Portuguesa (1999): Dicionário Universal Milénio. Língua Portuguesa, Lisboa, Texto Editora.

Dictionarium LATINO-LUSITANICUM AC JAPONICUM (1595): Dictionarium LatinoLusitanicum ac Japonicum, Amacusa (Japón), Companhia de Jesus.

ESTIENNE, Robert (1528-1543): Thesaurus linguae latina, París, Roberti Stephani.

FARIA, Eduardo Augusto de (1849): Novo Diccionario da Lingua Portugueza, Lisboa, Vianna.

FERNANDES, Francisco (1988): Dicionário ilustrado da língua portuguesa, Lisboa, Verbo.

FigueIREDO, António Cândido de (1899): Novo diccionario da língua portuguesa, Lisboa, Cardoso.

(1911): Novo diccionario da Lingua Portuguesa, Lisboa, Portugal-Brasil.

(1913): Pequeno diccionario da Lingua Portuguesa, Lisboa, Portugal-Brasil.

(1924): Pequeno Dicionário da Língua Portuguesa, Amadora, Bertrand.

FOLQMAN, Carlos (1755): Diccionario portuguez e latino, Lisboa, Officina de Miguel Monegal da Costa. 
FonseCA, José da (1829): Novo Diccionario da Lingua Portugueza, París, Aillaud.

(1830): Diccionario de Synonimos Portuguezes, Paris, Aillaud.

(1833): Novo diccionario da lingua portugueza seguido de um diccionario completo dos synonymos portuguezes, Paris, Aillaud.

FONSECA, Pedro José da (1762): Parvum lexicon latinum Lusitana, Lisboa, sn.

FONSECA, Simões da (c. 1900): Diccionario encyclopedico da lingua portuguesa, Rio de Janeiro-París, Garnier.

FONTINHA, Rodrigo (1957): Novo dicionário etimológico da lingua portuguesa, Porto, Barreiro.

FrANCO, António (1716) Indiculo Universal. Contem distinctos em suas classes os nomes de quazi todas as cousas que ha no mundo, \& os nomes de todas as Artes e Sciencias, Évora, Universidade.

GOMES, Aldónio (1999): Língua portuguesa: dicionário elementar, Lisboa, PCSE.

GonÇALVES, Joaquim Afonso (1831-1833): Dicionário Português-China / ChinaPortuguês, no estilo vulgar mandarim, e clássico geral, Macao, Colégio de São José.

GuEDES, Rui (1996) Grande dicionário da língua portuguesa, Lisboa, Bertrand.

Holanda Ferreira, Aurélio Buarque de (1941): Pequeno Dicionário Brasileiro da Língua Portuguesa, Rio de Janeiro-São Paulo, Civilizaçao Brasileira.

(1975): Novo dicionário da língua portuguesa, Rio de Janeiro, Nova Fronteira. - $\left(1986^{2}\right)$ : Novo dicionário da língua portuguesa, Rio de Janeiro, Nova Fronteira. (1977): Minidicionário da língua portuguesa, Rio de Janeiro, Nova Fronteira. (1980): Médio Dicionário-Dicionário da Língua Portuguesa, Rio de Janeiro, Nova Fronteira.

HouAISS, Antônio (2001/2009): Dicionário Houaiss da Língua Portuguesa, Rio de Janeiro, Objetiva.

LACERDA, José Maria de Almeida e Araujo Correia de (1860): Novissimo diccionario da lingua portugueza com reflexões criticas, Lisboa, Artus da Silva.

LA FAYETte, Levindo Castro de (1889): Novo Vocabulario Universal da Lingua Portugue$z a$, París, Garnier.

LELLO POPULAR (1948): Lello popular: novo dicionário ilustrado da língua portuguesa, Oporto, Lello \& Irmão. 
LELLO POPULAR (1952): Lello popular: novo dicionário ilustrado da língua portugues: segundo as bases do novo acordo ortográfico entre o Brasil e Portugal, Oporto, Lello \& Irmão.

LELLO ESCOLAR (1975): Lello escolar: novo dicionário ilustrado da língua portuguesa, com um epítome de gramática e regras ortográficas, uma lista de locuções latinas e estrangeiras e outra dos principais provérbios, Oporto, Lello \& Irmão.

LEXICOTECA (1985): Lexicoteca: moderno dicionário da língua portuguesa, Lisboa, Círculo de Leitores.

LEXILLELO (1989): Lexillelo: Novo dicionário da língua portuguesa, Oporto, Lello \& Irmão.

Ligorne, Bernardino Augusto (1936): Novo dicionário popular da lingua portuguêsa, Lisboa, Avelar Machado.

LISA: GRANDE DICIONÁRIO ENCICLOPÉDICO (1981): Lisa: grande dicionário enciclopédico da língua portuguesa, São Paulo, Lisa-Livros Horizonte.

London, A. J. (1701): A Compleat Account of the Portugueze Language. Being a Copious Dictionary of English with Portugueze and Portugueze with English, Londres, R. Jeanway (The Scolar Press Limited, Menston, 1970).

Machado, José Pedro (1949): Grande dicionário da língua portuguesa de António de Morais da Silva, Lisboa, Libânio da Silva.

(1952): Dicionário etimológico da língua portuguesa: com a mais antiga documentação escrita e conhecida de muitos dos vocábulos estudados, Lisboa, Confluência.

(1958-1971): Dicionário da Língua Portuguesa, Lisboa, Sociedade da Língua Portuguesa.

(1960): Dicionário da língua portuguesa, Lisboa, Didáctica.

(1961): Novo diccionario compacto da língua portuguesa, Lisboa, Confluência.

(1981): Grande Dicionário da Língua Portuguesa, Lisboa, Amigos do Livro.

(1984): Dicionário onomástico etimológico da língua portuguesa, Lisboa, Confluência.

(1991): Grande Dicionário da Língua Portuguesa, Acordo ortográfico da língua portuguesa, Lisboa, Círculo de Leitores.

(1999): Breve dicionário enciclopédico da língua portuguesa: revisto e actualizado, Lisboa, Dom Quixote. 
MARQUES, Joseph (1758): Nouveau dictionnaire des langues françoise et portugaise, Lisboa, Chez Jean Joseph Bernard.

(1764): Novo Diccionario das linguas portugueza, e francesa, Lisboa, Officina Patriarcal de Francisco Luiz Ameno.

MELHORAMENTOS: DICIONÁRIO PRÁTICO (1995): Melhoramentos: dicionário prático da língua portuguesa, São Paulo, Melhoramentos, D. L.

Mello, Alfredo Leite Pereira de (1949): Dicionário de Sinónimos da Língua Portuguesa, Lisboa, Tertúlia Edífica.

Mendes, Fernando (1904-1905): Diccionario da Lingua Portugueza (Prosodico e orthographico), Lisboa, Romano Torres impresor.

MICHAELIS: MODERNO DICIONÁRIO (1998): Michaelis: moderno dicionário da língua portuguesa, São Paulo, Melhoramentos, D. L.

MinsheU, John (1617): The Guide into the Tongues (Anglica. Cambro-Britanica. Belgica. Germanica. Gallica. Italica. Hispanica. Lusitanica seu Portugallica. Latina. Graeca. Hebrea), Londres, Joannem Browne.

Morais Silva, Antonio de (1789): Diccionario da lingua portugueza, Lisboa, Officina de Thaddeo Ferreira.

- $\left(1813^{2}\right)$ : Diccionario da lingua portugueza, Lisboa, Typogra-phia Lacerdina.

Moreno, Augusto (1921): Dicionário popular para Portugal e Brasil, Oporto, Portuguesa Ed.

(1934): Dicionario elementar da língua portuguesa, Porto, Portuguesa Ed.

(1936): Dicionario complementar da língua portuguesa, Porto, Educa-ção Nacional.

MoreIRA, Zenóbia Collares (2005): Dicionário da Língua Portuguesa Arcaica, Rio de Janeiro, Nova Fronteira.

NASCENTES, Antenor (1932-1952): Dicionário etimológico da língua portuguesa, Rio de Janeiro, Livr. Francisco Alves.

(1949): Dicionário básico do português do Brasil, São Paulo, Martins.

(1961-1967): Dicionário da língua portuguesa de la Academia Brasileira de Letras, Rio de Janeiro, Imprensa Nacional.

NeBRIJA, Antonio de (1492): Lexicon hoc est Dictionarium ex sermone latino in hispaniensem, Salamanca, s.n.

(1495): Dictionarium hispanum latinum, Salamanca, s. n. 
NEMNICH, Philippo Andrea (1801): Lexicon nosologicum polyglotton, Hamburgo, Müller.

Neuman, Henry (1800): A Marine Pocket-Dictionary, of the Italian, Spanish, Portuguese, and Germanic Languages, with An English-French, and French-English Index, Londres, Bonsor.

Novo Diccionario da Lingua Portugueza (1806): Novo Diccionario da Lingua Portugueza, Lisboa, Typographica Rollandiana.

NOVO DICIONÁRIO LELLO (1999): Novo dicionário Lello: estrutural, estilístico e sintáctico da língua portuguesa, Oporto, Lello \& Irmão.

Oliveyra, Selomoh de (1683): Vocabulario da lingua Portuguesa explicado em Hebraico, Amsterdam, $\mathrm{s} / \mathrm{n}$.

PEQUENO DICIONÁRIO BRASILEIRO (1938): Pequeno dicionário brasileiro da língua portuguesa, São Paulo, Civilização.

PEREIRA, Bento (1634): Prosodia in vocabularium trilingue, Latinum, Lusitanicum, \& Hispanicum, Évora, Carvalho.

(1647): Thesouro da lingoa portuguesa, Lisboa, Craesbeeck.

PereirA, João Félix (1885): Os Synonymos e Homonymos da Lingua Portuguesa, Lisboa, Typ. Lucas Evangelista Torres.

Pestana, José y J. A. Pereira (1913): O novo dicionário português, Oporto, s. n.

PINTO, Luís Maria da Silva (1832): Diccionario brasileiro da língua portuguesa, Ouro Preto, Typographia de Silva.

Rebelo Gonçalves, Francisco da Luz (1966): Vocabulário da Língua Portuguesa, Coimbra, Coimbra Ed.

REBOREDO, Amaro (1621): Raizes da lingua latina mostradas em hum tratado, e diccionario, Lisboa, Craesbeek.

(1623): Porta de Linguas ou modo muito accomodado para as entender, publicado primeiro com a tradução Espanhola. Agora acrescentada a Portuguesa com numeros interliniaes... com as raizes da Latina mostradas em hum compendio do Calepino... e ensinar brevemente, e para os estrangeiros que desejão a Portuguesa e a Espanhola, Lisboa, Craesbeeck.

RICHELET, Pierre (1680): Dictionnaire françoys contenant les mots \& les metières, Genève, chez Jean Herman Widerhold.

RoDRIGUES, Francisco Augusto Xavier (1912): Vocabulario ortografico da lingua portuguesa, Lisboa, Guedes \& Saraiva. 
Rodrigues, João (1603): Vocabulario da Língua do Japão. Com a declaração em português feita por alguns padres e irmãos da Companhia de Jesus, Nagasaki, Collegio de Japão da Companhia de Jesus.

Rodríguez CEBRAL, Dolores (1996): Dicionário da língua portuguesa, Madrid, Labrys.

RoQuete, José Inácio (1848): Diccionario da Lingua Portugueza de José da Fonseca, feito inteiramente de novo e consideravelmente augmentado por José Inácio Roquete, ParisLisboa, Guillard-Aillaud.

y José da Fonseca (1848): Diccionario dos Synonymos, Poetico e de Epithetos da Lingua Portugueza, Paris, Aillaud.

RuBIM, Brás da Costa (1853): Vocabulário brasileiro para servir de complemento aos dicionários da língua portuguesa, Rio de Janeiro, Typ. Dous de Dezembro.

SÃo Luís, Francisco de (1824): Ensaio sobre alguns synonymos da Lingua Portugueza, Lisboa, Academia Real das Sciencias.

SÉGUIER, Jaime (1989): Dicionário prático ilustrado: novo dicionário enciclopédico LusoBrasileiro, Oporto, Lello \& Irmão.

(1996): Dicionário prático ilustrado: novo dicionário enciclopédico LusoBrasileiro, ed. remodelada e actualizada conforme o acordo ortográfico entre Portugal e Brasil, Oporto, Lello \& Irmão.

SILVA, Fernando José da (1956): Dicionário da língua portuguesa: ortoépico, ortográfico, etimológico e arcaico, Oporto, Barreira.

SilveIRA Bueno, Francisco (1988): Grande dicionário etimológico-prosódico da língua portuguesa, São Paulo, LISA.

SOARES, António Joaquim de Macedo (1875): Diccionario brazileiro da lingua portuguesa, Rio de Janeiro, Typographia De G. Leuzinger \& Filhos.

Sociedade de Litteratos (Uma) (1844): Diccionario Universal da Lingua Portugueza, Lisboa, Typographia da Rocha.

SousA, Albano de (1917): Dicionário popular da língua portuguesa, Oporto, Joaquim $\mathbf{M}^{\mathrm{a}}$ da Costa.

TORRINHA, Francisco (1931): Moderno dicionário da língua portuguesa, Oporto, Simões Lopes.

(1942): Novo dicionário da língua portuguesa: para os estudantes e para o povo, Oporto, Barreira.

(1999): Dicionário da Língua Portuguesa, Lisboa, Notícias Editorial. 
VAldez, Manuel do Canto e Castro Mascarenhas (1864): Diccionario español-portugués, Lisboa, Imprensa Nacional.

VianA, Aniceto dos Reis Gonçalves (1909): Vocabulário Ortográfico e Ortoépico da Língua Portuguesa, Lisboa, Livraria Clássica.

(1913): Vocabulário ortográfico e remissivo, París-Lisboa, Aillaud-Bertrand. (1904): Apostilas aos diccionarios portugueses, Lisboa, Livraria Clássica, 2 vols.

VIEIRA, Frei Domingos Luís (1871-1874) Grande diccionario Portuguez ou thesouro da lingua portuguesa, Oporto, Chardron.

Vilela, Mário (1990): Dicionário do português básico, Oporto, Asa.

VITERBO, Frei Joaquim de Santa Rosa de (1798-1799): Elucidario das palavras, Lisboa, Thaddeo Ferreira.

(1825): Diccionario portatil das palavras, termos e frazes que em Portugal se usárão e que hoje regularmente se ignórão: resumido, correcto e accondicionado, Coimbra, Real Imprensa da Universidade.

VOCABULARIO DA LINGUA BRASÍlICA (1621): Vocabulario da lingua brasílica, facsímil por Plínio M. da Silva Ayrosa, São Paulo, Divisão de documentação Histórica e Social, 1938.

VOCABULÁRIO DA LÍNGUA BUCRE (1852: Vocabulário da língua Bucre, Rio de Janeiro, Rev. do Inst. Hist e Geogr. Brasileiro, Tomo XV, 5, pp. 60-77.

WAGENER, João Daniel (1811): Novo Diccionario portuguez-alemão e alemão-portuguez, Leipzig, Schwickert.

Wolf, E. M. (1971): Dicionário inverso da língua portuguesa, Moscú, Nanka.

ZuQuete, Afonso (1963-1966): Dicionário geral luso-brasileiro da língua portuguesa, Lisboa, Enciclopédia.

\section{REFERENCIAS BIBLIOGRÁFICAS}

Ayala CAStro, Marta Concepción (1996): «El Indiculus universalis de François Pomey», en M. Alvar Ezquerra, coord., Estudios de historia de la lexicografía del español, Málaga, Universidad de Málaga, pp. 49-59.

AZORÍN FERNÁNDEZ, Dolores (2000): Los diccionarios del español en su perspectiva histórica, Alicante, Universidad de Alicante. 
BAJO PÉREZ, Elena (2000): Diccionarios. Introducción a la historia de la lexicografía del español, Gijón, Trea.

CAsteleiro, João Malaca (1936): Estudo linguístico do $1^{\circ}$ Dicionário da Academia (1793), Lisboa, Academia das Ciências de Lisboa.

CodoñER, Carmen (1989): «Diccionarios bilingües latinos», en J. Borrego Nieto, J. J. Gómez Asencio y L. Santos Río, eds., Philologica II. Homenaje a D. Antonio Llorente, Salamanca, Universidad de Salamanca.

CorreiA, Maximino (1968): Alguns passos da vida de Amato Lusitano, Lisboa, Academia das Ciências.

DuBY, Georges (1997): La época de las catedrales, Barcelona, Círculo de lectores.

ETTINGER, Stefan (1989-1991): «Die zweisprachige Lexikographie mit Portugiesisch», en F. J. Hausmann, O. Reichmann, H. E. Wiegand y L. Zgusta, Wörterbücher: Ein internationales Handbuch zur Lexicographie/Dictionaries: An international Encyclopaedia of lexicography/Dictionnaires: Encyclopédie internationale de lexicographie, BerlinNew York, De Gruyter, 3 vols., III, pp. 3020-3030.

Leite de VAsconcelos, José (1932): Inventário dos Códices Alcobacenses, Lisboa, Biblioteca Nacional de Lisboa.

Lemos, Maximino de (1907): Amato Lusitano a sua vida e a sua obra, Porto, Eduardo Tavares Martins.

MAREllo, Carla (1989): Dizionari bilingui con schede sui dizionari italiani per francese, inglese, spagnolo, tedesco, Bologna, Zanichelli.

MEndes DE AlmeidA, Justino (1965): «Agostinho Barbosa: o segundo lexicógrafo português da língua latina», Revista de Guimarães, LXXV, 1/4, Janeiro-Dezembro, pp. 3140.

(1967): «Lexicógrafos portugueses da língua latina: A Prosódia de Bento Pereira», Revista de Guimarães, LXXVII, 1/2, Janeiro-Junho, pp. 5-17.

- (1969): «Lexicógrafos da língua latina em Portugal: Os dicionários de Pedro José da Fonseca», Revista de Guimarães, LXXIX, 1/2, Janeiro-Junho, pp. 5-40.

- (1969b): «Lexicógrafos da língua latina em Portugal: Vocabulário portuguez e latino de Bluteau», Revista de Guimarães, LXXIX, 1/2, Janeiro-Junho, pp. 198-210.

PIEL, Joseph (1960): «[Reseña a: José Pedro Machado, Dicionário etimologico da lingua portuguesa]», Revista de Filología, LXXII, pp. 449-455. 
SECO, Manuel (1987): Estudios de lexicografía española, Madrid, Paraninfo (Colección filológica).

SILBERT, Albert (1950): Autour de Francisco Solano Constancio, Coimbra, Tip. Coimbra.

TEYssier, Paul (1988): «Notícia de uma pesquisa sobre os dicionários de Jerónimo Cardoso», en R. Lorenzo, ed., Coloquio de Lexicografia, Actas do coloquio de lexicografía celebrado en Santiago de Compostela os días 27 e 28 de marzo de 1986, Santiago de Compostela, Universidade de Santiago de Compostela, Anexo 29 de Verba, Anuario Galego de Filoloxía, pp. 209-217.

VALDEMAR, António (2000): «Lusofonia en dicionário», Diário de Notícias, 29/03/2000.

VÁZQUEZ, Ignacio (2008): «Los orígenes (tardíos) de la lexicografía bilingüe españolportugués», Estudios de Lingüística de la Universidad de Alicante, XXII, pp. 263-277.

Verdelho, Evelina (1983): Sobre o Dicionário poético de Cândido Lusitano, Lisboa, Centro de Lingüística da Universidade.

Verdelho, Telmo (1993): «Aspectos da obra lexicográfica de Bento Pereira», en Gerold Hilty, ed., Actes du XXe Congrès International de Linguistique el Philologie Romanes Université de Zurich (6-11 avril 1992), Tübingen-Bassel, Francke, IV, pp. 777-785.

(1994): «Portuguiesisch: Lexicographie. Lexicografia», en Günther Holtus, Michael Metzeltin y Christian Schmitt, eds., Lexikon der romanistischen Linguistik (LRL). VI. 2. Galegisch, Portugiesisch, Tübingen, Max Niemeyer, pp. 673-692. Disponible en http://www.instituto-camoes.pt/cvc/hlp/biblioteca/lexicon3.pdf.

(1995): As origens da gramaticografia e da lexicografia latino-portuguesas, Aveiro, Instituto Nacional de Investigação Cientifica (Linguística, 18).

- (1999-2000): «O calepino em Portugal e a obra lexicográfica de Amaro Reboredo», Revista Portuguesa de Filologia, XXIII, pp. 125-149.

VILELA, Mário (1987): «O dicionário do século XX em comparação com os dicionários até agora existentes», en Actas do Congresso sobre a Situação Actual da Língua Portuguesa no Mundo, 1983, Lisboa, Instituto de Cultura e Língua Portuguesa, pp. 133-145.

(1988): «Os estudos de Lexicografia na Universidade do Porto», en Ramón Lorenzo, ed., Coloquio de Lexicografia. 27 e 28 de febreiro e $1^{\circ}$ de marzo de 1986, Santiago de Compostela, Universidad de Santiago de Compostela-Xunta de Galicia, pp. 199-201 (Verba. Anexo, 29). 